\title{
Analysis of the Relationship between Strategic Management and Human Resources Management in Informatics Services Company of Tehran Province
}

\author{
Amir Kompani ${ }^{1} \&$ Amir Babak Marjani ${ }^{2}$ \\ ${ }^{1}$ Master of Business Administration, Department of management, Qazvin Branch, Islamic Azad University, \\ Qazvin ,Iran \\ ${ }^{2}$ Assistant Professor, Department of management, Central Tehran Branch, Islamic Azad University, Tehran, \\ Iran \\ Correspondence: Amir Kompani, Master of Business Administration, Department of management, Qazvin \\ Branch, Islamic Azad University, Qazvin, Iran. E-mail: Amir_kompani@yahoo.com
}

Received: January 12, 2016

doi:10.5539/mas.v10n6p205
Accepted: February 25, 2016

Online Published: May 162016

URL: http://dx.doi.org/10.5539/mas.v10n6p205

\begin{abstract}
Concepts of strategic management and human resource management has long been of interest of researchers and various studies have been done on the relationship between these concepts. In general, researchers believe that the strategic management of the organization leaves a significant role in human resource management. In this regard, the present study is an attempt to examine this relationship in the form of a conceptual model includes 12 hypotheses that have been tested and evaluated in the informatics services company with a population of 740 people. In this study, the concept of strategic management in the form of three basic dimensions: 1) strategic planning, 2) execution of strategy, and 3) assessment strategy has been defined. Human resource management also consists of four main dimensions: 1) attraction and retain the human resources, 2) perceived organizational support, 3) normative and affective commitment, and 4) Optional behavior. The results showed that between strategic management and human resource management are positively and significantly correlated. As the results showed three independent variables of the study were able to predict more than half of dependent variable changes of human resource management, among which the variable of evaluation of strategy had the greatest role.
\end{abstract}

Keywords: human resource management, strategic management, strategy design, evaluation of strategy, strategy implementation

\section{Introduction}

In today's world, organizations are in constant competition. Intensity of competition increases every year and continuously all of organizations need to improve their organizational performance for the survival and growth. Today, after years of investigation, the elite and senior managers of organizations have concluded that the most important assets of companies are their human capitals. According to the conducted research a comprehensive human resource management increases organizational performance and is crucial in competitive continuous advantage. Human resource of an organization is a key resource for sustainable competitive advantage and is one of the main factors of organizational success, too. So, the effective management of human resources has become one of the most important issues facing organizations to achieve organizational goals. In recent decades, and following awareness of the importance of the strategic management of this important resource, adopt appropriate strategies to manage these resources, is the main concern of senior managers of organizations. Strategies determine a task how an organization in itself create conditions and necessary occasion for gaining competitive advantage. One of the most important task strategies of any organization are human resource strategies as an important factor plays a major role in the success of the organization. On the other hand, increased competition among organizations in recruiting specialist, changes in composition, values and expectations of the labor force, has caused managers understand the key element of human resources and beside having a strategic look at this source, decide to implementation of strategies of human resources (Qelich Lee, 2008).

Given a competitive environment in all the today's institutions especially in the informatics services company of 
Tehran it is requires organizations and managers and decision makers seeking competitive advantage to be able to survive in this environment and one of the issues among which is more important than other is human resources that with proper management it would be possible.

In order to accomplish the organization's mission that is to attract and recruit new technologies with a evolutional view and create sustainable value for society, the company from the commencement decided to make a plan for establishment of the needed infrastructure and the establishment of centers of the executive needs. The main mission and activity of this company is help to online automation and internet system of country in order to establish methods and instruments to provide better services. The extent of the needs and complexity of applicable solutions has led to company of informatics services of Tehran for respond its customers deploy a wide range of products and services and provide them. So, regarding the topics mentioned in this article we will try to explain the new concept of strategic management and new human resource management and its functional areas this questions to be addressed; Firstly, whether human resource management and strategic management is implemented by managers at a good level and secondly; is there a significant relationship between human resource management and strategic management or not?

\section{Theoretical Basis and Literature}

\subsection{Strategic Management}

Strategic management is the process of ensure the access to benefits caused by the application of appropriate strategies. According to this statement, an appropriate strategy is defined in accordance with the requirements of an organization at a given time (Davari and Sazzadeh, 2001).

Strategic management to reach success requires ways that enterprises should use it as a strategic management tool. Two ways that a company can use them as strategic management tools one is Mackenzie model and other is Balanced Scorecard which is provided below:

\subsubsection{The McKinsey 7S Model}

The McKinsey 7S mode is a framework and management model that in an effective and total look express seven factors to organize a company. These factors determine together the performance of the company. Companies large and small should examine these seven factors to ensure that strategies are implemented properly. All these factors are associated with each other and neglect of one can cause problems for the entire company.

\subsubsection{Balanced Scorecard System}

One of the most famous and best-known models of performance evaluation system is "Balanced Scorecard" expanded by "Kaplan and Norton" in 1992 and then has been improved. This model suggests to assess performance of each organization a series of balanced indicators should be used through which senior managers can have an overview to four key organizational aspects. These different aspects make possible answering the following four main questions:

1 - How is look to shareholders? (Financial perspective)

2 - In what areas should we good? (Internal perspective)

3 - How customers look us? (Customers perspective)

4 - How can we continue to improve and create value? (Learning and growth perspective) (Mišankov et al., 2014).

Balanced Scorecard involves financial indicators that indicate the results of past activities and moreover by taking into account the non-financial criteria that are prerequisites and driving for future financial performance completes them. "Kaplan and Norton," believe that having information on these four aspects, the problem of increase and accumulation of information by limiting used indicators is eliminated. The senior managers also will be forced to only focus on a limited number of critical indicators. In addition, the use of several different aspects of performance, prevent the sector optimization (Mišankov et al., 2014).

\subsection{Human Resource Management}

The attitude towards recruitment of persons in organization and the concepts of its scope has been changed. During the past decades people in the organization was seen as a force to perform specific functions.

But with the arrival of new technologies the nature of work was changed and work required the use of higher levels of skills and abilities. Willingness to participate in decision-making of subordinates was increased (Nick et al., 2015). Human resources management concept emerged in the $60 \mathrm{~s}$ of the twentieth century, but in the $80 \mathrm{~s}$ of the twentieth century entered in literature of management (Liudmila et al., 2014). In the 80s of the twentieth century the concept of human resource management by applying the rules of the final quality management in 
Japan by America, entered to field of management. They recognized that organization staff that called human resources is important resources that by valuable management approaches and combination of strategic management rules with human resources the organization can be managed efficiently (Inga, 2014). Human resources management can be effective in both the private sector and in the public sector. Human resource management can prevent somewhat institutional corruption in government agencies and in private companies increase organizational productivity through organizational health promotion (Nicholas et al., 2014).

\subsection{Strategic Human Resource Management}

Strategic management of human resources includes development and implementation of human resources strategy process in order linking the policies and procedures and methods of human resources with strategic goals and objectives of the organization.

The main purpose of strategic human resource management is strategic capabilities creation through assurance and making sure that the organization has skilled, committed and motivated staff to attempt to achieve sustainable competitive advantage. Its aim is to establish a sense of purposefulness and directed in environments often turbulent, thereby the business needs of the organization and the individual and collective needs of its employees are provided through the design and implementation of coherent and practical policies of human resources (A'rabi and Mahdieh, 2011).

\subsection{Literature}

1. Naqi Lu and colleagues in 2014 in a study entitled "evaluation of the effects of strategic human resource management and human resource management in organizational evolution" found the following results. Given the dramatic changes in the organizational social environments and the intensification of competition in the today's world, organizations more than ever, are looking to attract and more importantly, maintain and develop of people for implementation of their current and future processes. Today, the importance of human capital has expanded in all areas so that modern growth theory regards the density of human capital and even considers human capital as an influential factor in the economic development of the societies.

2. Gholamzadeh and colleagues in 2012 in a study entitled "the planning of strategy of human resources using the strategic reference points theory (Case Study: colored profile company of desert) achieved the following results. Human resource strategy is a pattern of decisions that is devoted to policies and procedures of human resources. In fact, it is the process of development and implementation of human resources to link strategy policies and practices of human resources with strategic goals of the organization.

3. Lojic and colleagues in 2014 in a study entitled strategic approach to human resources management achieved the following results. Human resource management is a new approach of management philosophy. The results show that human resource management resulting from changes in the modern world and to address people and use of their potential abilities. One of the major differences between human resources management and personnel management is strategic approach of human resources management. Strategic approach to human resources management is a developed process.

4. Nekorance and colleagues in 2012 in a study entitled strategic human resource management and army force found following conclusions. Human resource management is an important part of the strategic management of an organization that has focused on people. The main role of human resource management is linking organizational performance and organizational progression. To achieve organizational goals, the main tasks of senior managers of organization is design key strategies of human resources that are clear enough to can be properly used in a timely manner.

5. Bal and colleagues (2011) in a study entitled management of new human resources in the 21st century with a strategic view achieved the following results. Parallel with changes in the global environment, the quality of the labor force also changes. With the change in the labor force it is also necessary traditional management of personnel is changed to human resource management. By upgrading human resources strategic view in terms of academic literature will be achieved and will be very helpful in practice.

\section{Research Methodology}

The current study is an applied research and the method of data collection is descriptive and correlation. The population of this study consists of all managers at three levels of senior, middle and operational and experts working in the company of informatics services of Tehran province that the total number of is 740 people. In this study to provide the required data in a easier manner, we will use simple non-probability sampling method.

In this study, the independent variable is the strategic management and operationally measurement of it is carried 
out through a questionnaire that its validity and reliability have been approved, and also using a Likert scale has been scaled. And human resource management is the dependent variable. The questions used in the questionnaire in terms of content are related to facts or real data and regarding the type of questions in the sample group, will be considered closed.

Because answers to questions in order to facilitate the extraction and classification and analysis as well as ease in response are predicted as 5-point the 5-point that to each option a point numerical value is assigned to be studied. Library research and use of documents can be regarded as secondary data.

In order to determine the reliability test, Cronbach's alpha was used. This method is used for calculating the internal consistency of measurement tools that measure various characteristics. To use Cronbach's alpha method SPSS software has been used. To analyze the obtained data from the samples descriptive and inferential statistical methods were used. In fact, we have tested the variables using descriptive statistics. In this study descriptive statistics is used to determine the mean and standard deviation parameters. The used tests include:

- $\quad$ Regression Testing

- The correlation coefficient

- Kolmogorov-Smirnov test

\section{Data analysis}

\subsection{Descriptive Statistics}

The statistical sample distribution in terms of variables such as gender, age, education, work experience in organizations is showed in tables 1 through 4.

Table 1. Characteristics of the sample in terms of gender

\begin{tabular}{lll}
\hline frequency & percent & \\
\hline $\mathbf{1 0 4}$ & 42 & Female \\
$\mathbf{1 4 6}$ & 58 & Male \\
$\mathbf{2 5 0}$ & 100 & Total \\
\hline
\end{tabular}

Table 2. Characteristics of the sample in terms of age

\begin{tabular}{lll}
\hline frequency & percent & \\
\hline $\mathbf{9}$ & 4 & less than 20 \\
$\mathbf{1 3 1}$ & 52 & $20-30$ \\
$\mathbf{9 5}$ & 38 & $31-40$ \\
$\mathbf{1 5}$ & 6 & more than 40 \\
$\mathbf{2 5 0}$ & 100 & Total \\
\hline
\end{tabular}

Table 3. Characteristics of the sample in terms of education

\begin{tabular}{lll}
\hline frequency & percent & \\
\hline $\mathbf{2 5}$ & 10 & diploma or less \\
$\mathbf{1 6 0}$ & 64 & Associate and bachelor \\
$\mathbf{6 1}$ & 24 & Master \\
$\mathbf{4}$ & 2 & Doctoral and more \\
$\mathbf{2 5 0}$ & 100 & Total \\
\hline
\end{tabular}

Table 4. Characteristics of the sample in terms work experience in organizations

\begin{tabular}{lll}
\hline frequency & percent & \\
\hline $\mathbf{1 0 0}$ & 40 & Less than 5 years \\
$\mathbf{9 5}$ & 38 & $5-10$ years \\
$\mathbf{4 6}$ & 18 & $11-15$ years \\
$\mathbf{1 0}$ & 4 & More than 15 years \\
$\mathbf{2 5 0}$ & 100 & Total \\
\hline
\end{tabular}




\subsection{Inferential Statistics}

To assess the normal distribution of the dependent variable we use this test, if the result is that the data is normally distributed the Pearson correlation test will be used and in the case of non-abnormal of data distribution we will use Spearman correlation test that is nonparametric equivalent of Pearson test and the results are summarized in table 5 .

Table 5. The results of Kolmogorov - Smirnov

\begin{tabular}{|c|c|c|c|c|c|c|c|c|}
\hline $\begin{array}{l}\text { assessment } \\
\text { implementation }\end{array}$ & $\begin{array}{l}\text { strategy } \\
\text { assessment }\end{array}$ & $\begin{array}{l}\text { strategy } \\
\text { design }\end{array}$ & $\begin{array}{l}\text { human } \\
\text { resources } \\
\text { management }\end{array}$ & $\begin{array}{l}\text { optional } \\
\text { behavior }\end{array}$ & $\begin{array}{l}\text { affective } \\
\text { and } \\
\text { normative } \\
\text { commitment }\end{array}$ & $\begin{array}{l}\text { perceived } \\
\text { organizational } \\
\text { support }\end{array}$ & $\begin{array}{l}\text { Attraction } \\
\text { and } \\
\text { retention } \\
\text { of human } \\
\text { resources }\end{array}$ & \\
\hline $1 / 158$ & $1 / 571$ & $1 / 271$ & $1 / 715$ & $0 / 532$ & $1 / 678$ & $1 / 330$ & $1 / 115$ & $\begin{array}{l}\text { Kolmogorov } \\
\text { - Smirnov Z }\end{array}$ \\
\hline $0 / 140$ & $0 / 014$ & $0 / 079$ & $0 / 066$ & $0 / 939$ & $0 / 077$ & $0 / 058$ & $0 / 166$ & Significancy \\
\hline Normal & $\begin{array}{l}\text { Non- } \\
\text { Normal }\end{array}$ & Normal & Normal & Normal & Normal & Normal & Normal & result \\
\hline
\end{tabular}

Considering the results of test variables in the above table shows the result was normal for the independent variable (due to the significance level of 0.05 was obtained at an acceptable level) so to evaluate the correlation of variables parametric statistical methods, Pearson correlation coefficient test, can be used and the results of which are shown in Table 6.

Table 6. Correlation Test Results

\begin{tabular}{|c|c|c|c|c|}
\hline $\mathbf{p}$ & $\mathbf{r}$ & correlation coefficient & sub variable & variable \\
\hline $0 / 013$ & $0 / 249 * *$ & Pearson & strategy design & Attraction \\
\hline $0 / 000$ & $0 / 523 * *$ & Pearson & strategy implementation & retention \\
\hline $0 / 000$ & $0 / 748 * *$ & Pearson & strategy assessment & human resources \\
\hline $0 / 000$ & $0 / 369 * *$ & Pearson & strategy design & perceived \\
\hline $0 / 000$ & $0 / 568 * *$ & Pearson & strategy implementation & organizational \\
\hline $0 / 000$ & $0 / 649 * *$ & Pearson & strategy assessment & support \\
\hline $0 / 000$ & $0 / 420 * *$ & Pearson & strategy design & affective \\
\hline $0 / 000$ & $0 / 327 * *$ & Pearson & strategy implementation & normative \\
\hline $0 / 000$ & $0 / 400^{* *}$ & Pearson & strategy assessment & commitment \\
\hline $0 / 000$ & $0 / 395 * *$ & Pearson & strategy design & optional behavior \\
\hline $0 / 000$ & $0 / 457 * *$ & Pearson & strategy implementation & \\
\hline $0 / 000$ & $0 / 430 * *$ & Pearson & strategy assessment & \\
\hline $\mathrm{p}$ & $\mathrm{r}$ & correlation coefficient & sub variable & variable \\
\hline $0 / 000$ & $0 / 465 * *$ & Pearson & strategy design & Human resource \\
\hline $0 / 000$ & $0 / 567 * *$ & Pearson & strategy implementation & management \\
\hline $0 / 000$ & $0 / 726^{* *}$ & Pearson & strategy assessment & \\
\hline $0 / 000$ & $0 / 765 * *$ & & Strategic management & \\
\hline
\end{tabular}

**: Significance at the level of 0/01 error *: Significance at the level of $0 / 05$ error

The significance level for all variables in Table 6 has been obtained at an acceptable level of $\mathrm{P}<0 / 05$ indicating the existence of the relationship between independent variables and other variables of study. Also $r$ index is used to indicate the direction of the relationship and as seen in table 6 the relationship for all have been obtained positive. 
In general the main goal of multivariate regression use was that linear combination of variables is created in such a way showing us maximum correlation with the dependent variable. As a result of this linear combination can be used to predict the dependent variable as well we can evaluate the importance of each independent variable in intended predict. To assess the normal distribution of the dependent variable and errors of model Kolmogorov Smirnov will be used and the results of which are summarized in Table 7.

Table 7. The results of Kolmogorov - Smirnov

\begin{tabular}{|c|c|c|c|c|c|}
\hline $\begin{array}{l}\text { Standard errors of the } \\
\text { predicted value of } \\
\text { human resource } \\
\text { management }\end{array}$ & $\begin{array}{l}\text { Standard errors of the } \\
\text { predicted value of } \\
\text { values attract and } \\
\text { retain human } \\
\text { resourcesr }\end{array}$ & $\begin{array}{l}\text { Standard errors of the } \\
\text { predicted value of } \\
\text { perceived } \\
\text { organizational support }\end{array}$ & $\begin{array}{l}\text { Standard errors of the } \\
\text { predicted value of } \\
\text { affective and } \\
\text { normative commitment }\end{array}$ & $\begin{array}{l}\text { Standard errors } \\
\text { of the predicted } \\
\text { value of optional } \\
\text { behavior }\end{array}$ & \\
\hline $0 / 929$ & $1 / 107$ & $0 / 758$ & $0 / 614$ & $1 / 003$ & $\begin{array}{l}\text { Kolmogorov - } \\
\text { Smirnov Z }\end{array}$ \\
\hline $0 / 354$ & $0 / 172$ & $0 / 614$ & $0 / 845$ & $0 / 266$ & significance \\
\hline
\end{tabular}

As you can see fitness of the Kolmogorov - Smirnov at the level of significance are more than 0/05 meaning the dependent variable and the residuals are normally distributed and indicating the fitness of the model. The results of the regression analysis of research are shown in table 8 .

Table 8. Regression analysis results

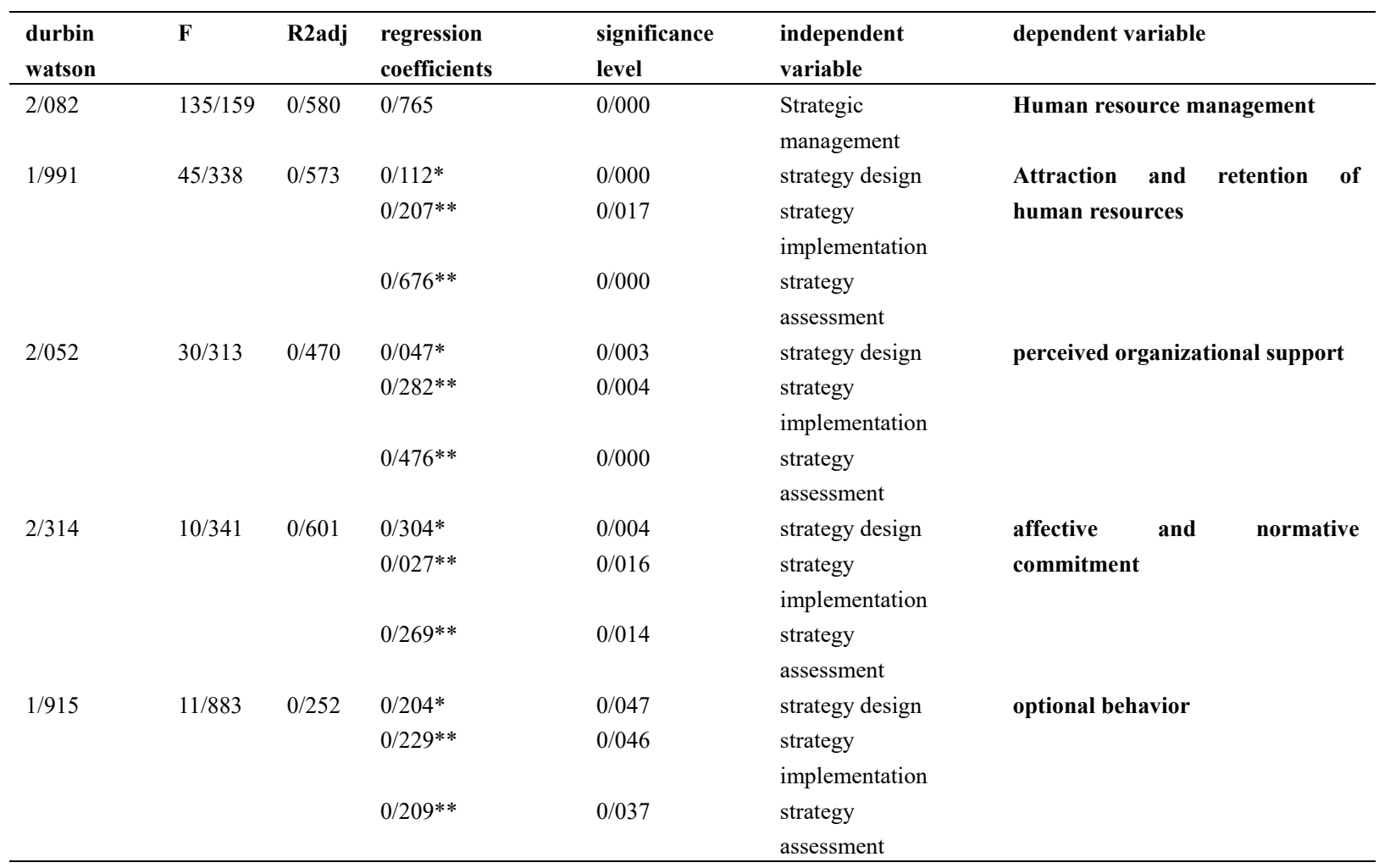

\footnotetext{
**: Significance at the level of 0/01 error *: Significance at the level of 0/05 error
}

$\mathrm{R} 2$ in the above table is adjusted squared of known multiple correlation coefficient. This coefficient shows the explanation of variance and the dependent variable changes by independent variables. The value of this coefficient varies between 0 and 1 . The more this coefficient is closer to one it shows that independent variables have been able to explain a large amount of variance of the dependent variable. In the above table this statistics for equation is $0 / 58$ indicating three independent variables could predict 58 percent of our dependent variable changes. 
F indicates whether regression model is an appropriate model or not. In other words, do the independent variables can explain the dependent variable appropriately or not? The recognition of this issue with significance of $\mathrm{F}$ at error level of smaller or higher than $0 / 05$ is possible that $\mathrm{F}$ was obtained in this equation 135/159 indicating this statistic is significant due to obtained amount showing the power of independent variables of research in explaining the rate of changes the variance of dependent variables.

\section{Conclusion}

According to the results of study questions in the strategy design part in the organization, the respondents' view is considered above average and almost it can be said that the level of assessment is good. But in the evaluation and implementation part respondents' view is considered lower than average indicating the relative weakness of the organization in the relevant fields. Finally in the human resources management part but respondents view indicating the strengths of the organization in human resource management in the organization. The mean scores of views were considered above average. As can be seen, 146 out of 250 equivalent $58 \%$ of participants are men and the rest 104 or $42 \%$ are women. The majority of cases are male. Also $44 \%$ of respondents (i.e. 109 participants) and 56\% are married (i.e. 141 participants). In terms of age $4 \%$ had less than 20 years, $52 \%$ between 20 and 30 and $38 \%$ between 31 to 40 years and the remaining $6 \%$ were over 40 years old. The educational level of $10 \%$ of participants (25 participants) was diploma or less, $64 \%$ of participants were associate and undergraduate (160 participants), $24 \%$ were graduate students (25 participants), and $2 \%$ of the participants (4 participants), were $\mathrm{PhD}$. In terms of job position in the organization, 10 participants (4 percent) were manager, 115 participants (46 percent) expert, 25 participants (10 percent) supervisor and 100 remaining participants (40 percent) were incumbent. Finally, in terms of organizational experience 100 participants (40 percent) had less than 5 years of experience, 95 of them (38 percent) between 5 and 10 years, 46 participants between 11 to 15 years, and 10 remaining participants ( 4 percent), had more than 15 years of experience.

The results of this study were in line with a lot of research, including the study of Naqi lu and colleagues in 1393. This study showed that the role of human resource development should be stronger in achieving the goals of the organization and a relationship should be established between goals and human resource development activities with organizational goals.

Rahimnia and Luqmani also conducted a study in 2013 and the aim of this paper is to examine the issue of diversity management in a comprehensive approach in order to help managers to deal with the inevitable issue of workforce diversity by a strategic approach and operate this valuable tool for creating competitive advantages for their organizations. Gholamzadeh and Jalali also in a research entitled Codification of human resources strategy using the theory of strategic reference points (Case Study: Desert colored profile company) in 2012 tried to after coordinate processing of obtained data determine the strategic Coordinates of jobs and identify the appropriate strategic pattern of each category of jobs.

In line with the research subject Ranko and his colleagues also in a research entitled strategic approach to managing human resources, in this paper clarify the characteristics of the human resources management and personnel management and their differences and specify the current approach to human resource management. Allen and Wright (2006) also in a study entitled the human resource management and strategic management conducted a review and descriptive study about the relationship between two variables of the study.

\section{Suggestions for Future Researches}

- Respectful researchers can assess this area with other existing models for assessing human resource management and implement in this issue.

- It also can be for strategic human resource management design a standard in accordance with what exists in literature or on the site of large and successful companies in international arena or the existing companies, in other words, compare the organization undergone study with it and present solutions to improve the projects.

\section{Limitations of the Study}

- Considering that in addition to strategic management there are other factors that can affect the management of human resources, so not reviewing the other factors besides factors presented in this study, reduce the accuracy of the research.

- Due to limitations of the questionnaire questions it was possible that the ultimate goal of study comprehensively be fulfilled during the design of the questions of questionnaire. So this is other limitations that we faced in this research. 


\section{References}

Bal, Y. (2011). The new human resources management in the 21st century: A strategic view. Annual Conference on Innovations in Business \& Management. London, UK.

Davari, D., Shanehsaz, Z., \& Mohammad, H. J. (2001). Strategic Management, Spring, pp. 41 -79.

Gholamzadeh, D., \& Jalali, S., (2014). Codification of the theory of human resource strategy using strategic reference points theory (Case Study: Desert colored profile company). State Administration, 4(10), 137 -152 .

Inga, L., Gunta, M., \& Olga, S. (2014). Human resource management models: aspects of knowledge management and corporate social responsibility. Procedia-Social and Behavioral Sciences, 110(2014 ) 577-586.

Jaroslav, N., \& Eva, R. (2014). Strategic Management Of Human Resource And The Slovak Armed Forces. Journal of Defense Resources Management, 5, 1(8).

Mária, M., \& Katarína, K. (2014), Strategic implementation as a part of strategic management. Procedia - Social and Behavioral Sciences, 110(2014), $861-870$.

Naqi, L., Esfandia, R., Naqi, L., Maryam, N., \& Jahanbakhsh, L. (2012). The effect of strategic human resource management and human resource management in organizational development. Change management and innovation in enabling management conference.

Nik, H., Nik, A., \& Jamaliah, S. (2015). Enhancing the Governance of Government Linked Companies via Strategic Management Accounting Practices and Value Creation. Procedia Economics and Finance, 28(2015), $222-229$.

Nikolaos, P., Antonakasa, Nikolaos, K., \& Ioannis, S. (2014). Human Resource Management's role in the public sector and the level of corruption: The case of Greek Tax Administration. Procedia - Social and Behavioral Sciences, $148(2014), 455-462$.

Qelich, L. B. (2007). The excellence of human resources (assessment, planning and improvement), Tehran: Saramad (affiliated with the Institute for Productivity and Human Resources).

\section{Copyrights}

Copyright for this article is retained by the author(s), with first publication rights granted to the journal.

This is an open-access article distributed under the terms and conditions of the Creative Commons Attribution license (http://creativecommons.org/licenses/by/3.0/). 